\title{
The Principle of Humanism-The Fundamental Principle of Inclusive Education
}

\author{
Regina K. Nabiullina ${ }^{1}$ \\ ${ }^{1}$ Kazan (Volga region) Federal University, Kazan, Russia \\ Correspondence: Regina K. Nabiullina, Kazan (Volga region) Federal University, Kremlyovskaya Street 18, \\ Kazan, 420008, Russia.
}

Received: December 29, 2014

Accepted: January 22, 2015 Online Published: February 11, 2015

doi: $10.5539 /$ res.v $7 \mathrm{n} 4 \mathrm{p} 73$

URL: http://dx.doi.org/10.5539/res.v7n4p73

\begin{abstract}
The article considers the development of humanistic approach in inclusive education. Inclusive education development and its reflection in regulatory documents in Russia and abroad are presented from historical retrospective point of view. To solve the given problem the professional community puts forward a number of objectives. These objecives are being implemented in several directions. One of the directions is the application of modern means and technologies. The introduction of interactive technologies is supposed to use interactive equipment and specialized software which help to establish child's contacts with adults and other children in the group.
\end{abstract}

Keywords: inclusive education, integration, humanistic approach, interactive technologies, case-studies, case-method

\section{Introduction}

The major objective of modern society is the development if inclusive processes to provide social equality, qualitative education and culture of open relationship.

This task may be solved by the formation of the inclusive policy which makes the basis of inclusive education development, social inclusion, inclusive culture and inclusive practice (Akhmetzyanova, 2014).

International legislation in the sphere of inclusive education covers a more than half of the century period. Such documents as the Universal declaration of human rights (1948), the Convention against Discrimination in Education (1960), the UN Convention on the Rights of the Child (1989), International Covenant on Economic, Social and Cultural Rights (1966), the Salamanca statement secure the right of every human for affordable education at all its stages and introduce the ban on any discrimination in the sphere of education.

One of the major principles of Russia state policy in the sphere of education is based on the accessibility of education. The Federal Law "About education in the Russian Federation" defines inclusive education as "the provision of equal access to education for all categories of learners with the variety of specific educational needs and individual abilities taken into consideration". Article 79 of the Law regulates the obtaining of education by learners with special needs (SN). In the papers of UN Salamanc, Jomtien and Geneve conferences the notion "inclusion" means integration of persons with SN and persons with "political, race, ethnical, gender and language variety" as well (Woolfson Richard ).

Summing up the above mentioned it is possible to say that inclusive education is in its essence the process of general education development which assumes the implementation of the humanistic principle of education affordability for everyone with adaptation to different needs of all children. Such methodological approach provides the access to education for children with special needs as well.

\section{Methodological Framework}

Inclusive education is regarded in pedagogics as the process of general education development which implies the accessibility of education for everyone with adaptation to children with special needs so as to provide the access to education for these children (Herzen, 2008). The belief that any discrimination of a personality should be eliminated and equal attitude to all people should be implemented makes its basis. The idea of inclusive education as a pedagogical system combining special and general education was put forward by L. S. Vygotski, 
who was the first to prove the necessity of such an approach in the 30s of the XXth century. His ideas about the connection between social activity, social surrounding and individual development of a human made the methodological basis of social-educational integration of children with special needs.

Inclusive education tends to develop the methodology oriented at children and admitting that all children are individuals with different needs in education. Inclusive education makes efforts to work out a humanistic approach to teaching and learning which will be more flexible to satisfy different needs in education. If teaching and learning become more effective as a result of changes that inclusive education introduces then everyone wins, not only children with special needs.

Inclusion as a humanistic form of "a special approach to disability" has been caused by the necessity to change the general system, to eliminate existing barriers so as to allow every disabled person to be a full participant of academic and social life of an educational institution. The methodological basis of such systems should be the unified system of fundamental and moral laws aimed to develop the unified space for Human, Society and Nature life (Malofeyev, 2012).

\section{Results and Discussions}

Inclusive education comprises humane conceptual ideas. The process of inclusive education is the process within the frames of which the given community provides humane educational conditions to realize the maximum of every individual's potential. The objective of inclusive education cannot be solved from the outside, it can be solved by the community within itself. A step forward to those who are in trouble, who are dependent on surrounding people as they cannot survive without them, is the essence of the humanistic concept of inclusion. This is a mutual adaptation of the individual and society to each other. This is such an educational process in the course of which not only the individual adapts to the community of classmates or group-mates but the society itself makes necessary steps to adapt to this individual.

As for the major objectives aimed to solve humanistic issues of inclusive education content there may be the following ones:

- Improvement of normative-legal, scientific-methodical, financial-economic support aimed to introduce the humane content into inclusive education;

- Development of state educational standards, educational developmental environment for children with special educational needs by means of psychological-pedagogical and medical-social support along with academic subjects;

- Ensuring access to the social environment in classrooms, development and application of special didactic materials, rehabilitation means of teaching;

- Improvement of training and retraining for the teaching staff working and creating in humanistic conditions of inclusive education;

- Involvement of parents who have children with special educational needs in the participation in a teaching-rehabilitation process for the purpose to increase its effectiveness.

These objectives are being implemented in several directions. First of all inclusive education can be obtained in educational institutions of a general type which have provided special conditions for teaching pupils with special needs. The humanity of didactical approaches and content of inclusive education is in the fact that children with special needs may study according to individual curriculums in specialized classes of comprehensive schools or in conditions of home learning depending on the child's health state. For children with heavy intellectual disability and multiple impairments it is possible to study in correctional-developmental rehabilitation schools (Kurth, J.). Education in a special integrated class is realized according to individual curriculums and programs mutually elaborated by teachers of this class and members of the Council on the basis of educational programs recommended by psychological-medical and psychological-pedagogical commissions (Alekhina, 2011).

The humanistic criterion of the educational environment quality is the ability to provide a child with personality development and integration in society. First of all it means the transition to a real interaction and communication of all children without any differences. Various forms of mutual activity in conditions of barrier-free environment are used to help children to master standards of social behaviour and acquire the experience of their application within the process of interaction.

The second significant level of integration is connected with the definition of a curriculum and programs which take into account the interests of all categories of children (common children and children with special needs). It is important to state the correlation of working time within differentiated teaching process to give everyone an 
opportunity to study according to their own performance. Not less important condition is the child's participation in the assessment of their learning achievements and personality development successes (Alekhina, 2011).

As the researchers of inclusive education issues declare, the result of inclusive education and upbringing increases in mutual education process in comparison with the traditional frontal teaching. Creative methods of teaching such as drama, creating video, different group projects etc. are used in it. All this taken together give additional opportunities, new strength. One of the humanistic objectives of this work is to make a child's participation in the society more meaningful.

To implement these humanistic ideas means and technologies are necessary; they should be universal as education is for everyone and is at the same time individual as everyone has their own educational abilities, needs and demands. Modern interactive technologies have such opportunities; they allow to introduce inclusive education in full. Interactive (inter-mutual, act - take action) means to interact, to communicate, to dialogue with somebody or a computer. Thus, interactive teaching is based on learner's interaction with the learning surrounding, learning environment which serves as the sphere for mastering experience. The learning surrounding (or learning environment) acts as the reality in which the participants find the sphere of this experience (Hoffman, 2011).

The peculiarity of interactive technologies is that their practical application is possible only in case of teachers' and pupil's mutual activity. The following is characteristic for them:

- "Forced" activation of learners' thinking regardless their immediate wish;

- Support of learners' involvement in the educational process as their activity should be sustainable and some times quite long;

- Independent development of decisions, high degree of schoolchildren motivation and emotiveness;

- Ongoing interaction of all present in class in the process of dialogue forms of inclusive education;

- Mmanifestation of a teacher and a pupil's self-organization (Sapeghin, 2010).

We believe that interactive technologies perform their best to become a part of the theory and practice of inclusive education as active interactions make its basis; they allow a learner to become not only a participant of lessons but also a subject of the educational process and what is more important to become a subject of actual communicative activity that promotes inner intention to master knowledge and creative development.

\section{Conclusion}

The application of interactive equipment and specialized software helps to provide a contact between a child and an adult, between children in group; to organize children's mutual work; to create a lot of case studies where individual features of every child and a group of children are taken into account; to try different variants of solutions; to save every child's working results in the accessible place.

Case studies - a learning situation specially elaborated on the basis of actual material for the purpose of further discussion in class. In the course of discussion children learn to act in a team, to analyze and take management solutions. The ideas of a case-study (method of situational training) or case-method are quite simple:

- The emphasis of learning is transferred not to the mastering of ready given knowledge but to its obtaining, to teacher and pupil's and pupil and pupil's co-creation; hence there is a fundamental difference of the case method from traditional methods - democracy of the process aimed to obtain knowledge when a pupil is equal with other pupils and a teacher in the course of problem discussion;

- Case method allows to overcome "aridity", emotional detachment in material presentation as a well organized discussion of the case (situation, event) is similar to a theatrical performance;

- Case study method promotes pupils' independent thinking, ability to listen and take an alternative point of view and prove their own.

Interactive technologies allow to teach each pupil according to the program which corresponds to their abilities and at the same time which is complicated enough for them (Nigmatov, 2013).

Thus, inclusive padagogics which we name humane pedagogics suggests the creation of comfortable social and psychological conditions for all categories of learners and their involvement and active participation in educational processes and independent decision making.

\section{Acknowledgments}

The work is performed according to the Russian Government Program of Competitive Growth of Kazan Federal 


\section{University}

\section{References}

Akhmetzyanova, A. I. (2014). Organization of inclusive education for persons with special needs in Kazan federal University. Journal Education and self-development, 2, 40-43.

Akhmetzyanova, A. I. (2014). Spatial and temporal elements of anticipation consistency of children with general speech retardation. American Journal of Applied Sciences, 11(7), 1031-1035. http://dx.doi.org/10.3844/ajassp.2014.1031.1035

Alekhina, S. V. (2011). Materials of international scientific conference (pp. 244-252). Moscow city psych.-ped. university.

Herzen, A. I. (2008). Inclusive education: Issues of educational policy and system improvement. In Materials of the international conference (pp. 225-229). SPb.: Publishing house of RSPU.

Hoffman, E. M. (2011). Relationships between inclusion teachers and their students: Perspectives from a middle school (p. 71). Dissertation Abstracts International Section A: Humanities and Social Sciences.

Kurth, J., \& Mastergeorge, A. (2009). Individual Education Plan Goals and Services for Adolescents with Autism: Impact of Age and Educational Setting. The Journal of Special Education, 44(3), 146-160. http://dx.doi.org/10.1177/0022466908329825

Malofeyev, N. N. (2012). Panegyric on inclusion or a Speech in defence of myself. Upbringing and teaching children with impairments, 1, 35-41.

Nigmatov, Z. G. (2013). Technologies of interactive learning in the system of inclusive education (pp. 221-226). Collected materials of International scientific conference "Modern problems of secondary and higher professional school didactics". Kazan: "Pechat- Service XXI century".

Sapeghin, K. V. (2010). Educational technology "Portfolio". Director of rural school, 3, 49-50.

Woolfson R., \& Truswell, E. (2005). Do classroom assistants work? Educational Research, 47(1), 63-75. http://dx.doi.org/10.1080/0013188042000337569

\section{Copyrights}

Copyright for this article is retained by the author(s), with first publication rights granted to the journal. This is an open-access article distributed under the terms and conditions of the Creative Commons Attribution license (http://creativecommons.org/licenses/by/3.0/). 